\title{
Research on Digital Technology in Environmental Art Design Xi Huang ${ }^{1, a}$ \\ ${ }^{1}$ Wuchang Institute of Technology, Wuhan, Hubei, 430065 \\ ${ }^{a}$ email
}

Keywords: Digital Technology, Environmental Art Design, Technology Study

\begin{abstract}
Today, the rapid development of society, every day there are endless new things appear, the use of digital technology in the design of science and technology is also an important manifestation of the development of science and technology, the traditional design means can not meet people's growing aesthetic requirements and the development of aesthetic concepts. The emergence of multimedia and the development of computer-aided design, digital technology more and more into the design, making the design with a new life, artistic expression techniques have a richer means.
\end{abstract}

\section{Introduction}

Environmental art design development is changing, is a new discipline, its theoretical system has not yet formed a complete system of the system. There is no consensus on the definition of the concept of the object of the study of environmental art and its design and the division of the scope of work. Environmental art theorist Dorber for the concept of environmental art design of the whole release: "environmental design is one of the many branches of art, space is more huge than the building, the scope of more extensive than the plan, from the humanities more Full of human emotions. Environmental art design pervasive, all-encompassing, is a long-standing attention to the traditional art, environmental art design from the practice has been deeply demonstrated its ability to influence the environment, to give the environment a new order, landscaping The survival of the region, to enhance the human environment for the pursuit of the surrounding environment. Dobo for the definition of the meaning of the environment is accurate, accurate positioning, and the whole of the definition of the whole though the demon art point of view, but its description of the connotation of environmental art To a large extent beyond the past for the environmental art design of the stereotype. Todber's definition of environmental art as a rich background, a wide range of science, with the general visual art features, both with the characteristics of science and engineering features. Dob's definition of deep understanding and taste, I understand the environmental art Defined as: environmental art is the art of human interaction and around and living environment.

\section{Characteristics of Modern Digital Environment Art Design}

In the traditional environmental art design, the rendering of the renderings depends on the manual operation. The modification of the local details will cost a lot of manpower, material and financial resources, and may even negate the designer's design. However, the use of digital performance technology, the designer can be very convenient Quick to modify and improve the effect of the map, making the local problems and even global problems are corrected in a timely manner. The first material basis is to use the digital process in the environmental design, the composition of the environment of the various types of resources itself is one of the most direct material composition. In the process of digitization, we will further classify these resources. Although there are many ways to classify substances, the classification of resources for computers will be more simplified because the computer accepts information that has its own unique form and requirements. Need to picture, digital and other elements of digital processing and then enter the computer. On the basis of the composition of these basic elements, we can use the database for storage collation and collation, and further provide a password such as search, of course, the database type, there can be a lot, we have different relationships between the database Description and definition to form a relational 
database to meet a higher level of application, and relational data itself is also a simulation of the real world resources of a relationship between the technology, relative to the simple process of digital resources, digital database has a higher and More stringent definitions and standards.

Traditional design of the renderings depends on the manual operation, local details of the modification will cost a lot of manpower and material resources, and may even negate the designer's design, but the use of digital performance technology, designers can easily and quickly To be modified and perfected, so that local problems and even global problems are corrected in a timely manner, reducing duplication of effort, help to improve efficiency, effectively integrate the various programs organically. Digital technology based on a variety of software, in the design practice, the color display is very rich, the choice of material range is also very wide, but in showing the specific design results, the computer performance technology for the line ratio, color range and volume Out of control accuracy, obliterated the ring art design program in the ambiguity and randomness, making the design of the designer's lack of inspiration sparks. But also because some designers are not familiar with the design software, as well as the limitations of the design software itself, the designer a lot of good design ideas can not be put into the design practice. These factors make the design work can not fully reflect the designer's ideas, inspiration, a serious constraint on the designers engaged in the design of the hands and feet, limiting the designer's design freedom.

\section{Digital Design of Environmental Art Design}

In the digital age, the core of environmental art design is the integration of technology and design, digital technology to the field of environmental design has brought great changes and effects. By analyzing and studying the application of digital technology in environmental art design practice, enlightening design thinking, developing imagination and creativity to cultivate the specialized design talents needed to meet the needs of the times. For a long time, the expression of environmental art design is mainly based on the information carrier, the role of information is indispensable, especially in the design of the concept stage, the analysis stage and design expression stage is particularly prominent. Now the use of digital technology and tools are used to show a wide range of graphic information has become mainstream, this trend has become an important element of design thinking. Different levels of science and technology development level is different, the use of technical tools are also very different, these differences often affect or even determine the different design thinking mode. We are familiar with the traditional method of illustration is to use manual drawings, hand drawings, models, etc. to convey the designer's intention to the designer's digital technology mature and into the environmental art design, making the way to convey the space icon is revolutionary Of the change, the designer's professional way of thinking is almost subversive change. The design pattern of environmental art design has been influenced and changed by the change of design media, the progress of application technology, and the development of digital technology media from the past, mainly to pen and paper. The reason is, on the one hand because the digital era itself has a unique appeal, affecting the environmental art design industry, on the other hand is the audience demand for the United States increasingly strong.

With the economic and social progress, the development of science and technology, human thinking mode is also constantly developing, thinking system is gradually diversified. From the initial anthropomorphic thinking structure to the smooth transition of human spontaneous dialectical thinking, modern science and technology has been the emergence of new results, energy conservation theorem, evolution theory, cytology, and then to modern science and technology information digital technology explosion leap, Human thinking mode is constantly changing from quantitative to qualitative development.

\section{Application of Digital Technology in Environmental Art Design}

In today's digital age, modern environmental art design has revolutionized, because it incorporates digital technology and network technology, mainly for the immersion design and non-immersion 
design. Based on the virtual reality technology classification can be divided into model-based immersion design and other two designs, model-based immersion design in the general display will not be applied, mainly because of its high cost. High technical content, relatively immature. So the following only discusses non-submerged display about image-based design, model-based design. Digital technology based on a variety of software, in the design practice, the color display is very rich, the choice of material range is also very wide, but in showing the specific design results, the computer performance technology for the line ratio, color range and volume Out of control accuracy, obliterated the ring art design program in the ambiguity and randomness, making the design of the designer's lack of inspiration sparks. But also because some designers are not familiar with the design software, as well as the limitations of the design software itself, the designer a lot of good design ideas can not be put into the design practice. These factors make the design work can not fully reflect the designer's ideas, inspiration, a serious constraint on the designers engaged in the design of the hands and feet, limiting the designer's design freedom.

Under normal circumstances, the development of architectural design, including analysis and research, comprehensive evaluation of the more typical steps, that is, different design stages of different design objects to varying degrees of abstract design. The traditional design of the form of expression is generally based on the expression of information. This stage of the design of the icon is often reflected in the early analysis of the research process, mostly non-specific shape of the two-dimensional analysis of the main map, with strong abstraction and more instability. After the early collection and analysis, classification and finishing, the relevant theory and design concept gradually become plump, get the information system logic is clear, this process is reflected in the logic of clear thinking and relatively vague abstract thinking interaction results The With the gradual clarification of the program and the idea of continuous verification and scrutiny requirements, the expression has gradually become rich and strict, such as flat, vertical and profile with a more rigorous size elements; perspective, axis mapping And bird's-eye view is more vivid and vivid; there are physical model of the performance is more intuitive and convenient. These different ways of expression are also more slowly appear in the design process.

Traditional design design in the architectural design of the main practicality is the design concept and intent from the abstract image into a more specific image. On the one hand it is the design of the abstract concept map into a concrete and real image, such as from a particular orientation observed architectural space perspective sketch, etc., although the traditional way of thinking thinking has an irreplaceable advantage, but its own Also has a very deadly limitations. For example, some designers have a new idea in the bud, but because of lack of experience and performance skills, so that the idea can not vividly on paper, and thus died; because the graphical way of visual limitations, people mistakenly understand the performance of three-dimensional space For the plane space. These limitations stem from the traditional method of illustration itself, hand drawn sketch and the use of elements is not accurate enough, lack of flexibility, and through the drawings to communicate between the design information caused by the larger loss of elements, efficiency is also low, especially In the more abstract design work and the specific reality of the design content of the middle of the omission and different.

In order to overcome the shortcomings of classical formalism in the use of pictorial information, modern architecturalism advocates "form obedience to function", focusing on the connotation of design work rather than focusing on the appearance of the form, while the social environment, science Technology and other factors as one of the design factors, architectural design from the traditional single linear thinking evolved into focus on both internal and external two-way design process. Through the use of digital representation, you can have a wider range of information sharing, more uniform and standardized information model, more abundant network collaboration, these methods are conducive to get rid of the traditional graphic thinking defects, making the design more diverse multi-dimensional, colorful.

The digital media makes the old media technology take on new roles and has revolutionary significance. Set of elements, interactive, intelligent, selectivity and initiative, the simplicity of the text as a whole, to provide us with accurate, efficient service. In the architectural design, the 
construction information model and the civil engineering information model are based on the highly integrated professional information system, in the same information exchange standard specification, the construction process of each stage of the various types of work to connect, which is digital technology One of the advantages, through this connectivity, can effectively integrate a variety of design resources, management resources, construction resources, making the design a harmonious and efficient organism.

\section{Conclusion}

The development of the times, the progress of science and technology, makes the division of labor more and more fine, any industry is no longer a simple fortress, open the door, learn from each other, interdisciplinary integration and penetration, is the necessary rapid development of their respective industries condition. Today's society is also difficult to re-emergence of all-rounder and generalists, knowledge of the explosion of the update, making every natural person in the face of this ever-changing world are powerless, want to achieve success in their respective industries and fields, we must use the power of cooperation. Cooperation is the theme of today's social development, cooperation between countries, regional and regional cooperation, cooperation between people, discipline and discipline cooperation. Art design has always been a very comprehensive discipline, a design work often involves the psychology, culture, market, science and technology and so on, and the traditional art has a big difference. The maturity of computer technology makes the combination of art design and computer science extremely close. Digital ring art design not only makes the audience more convenient and intuitive understanding of the designer's intention, but also allows designers to more thoroughly to the world to show their own design ideas; the same time digital technology makes the art design more exciting gorgeous, is the traditional design Can not be replaced, the art design to two height, - was a new life.

\section{References}

[1] Lan Qiuping, Li Lijun, Yang Bo. Study and Application of Interactive Technology between 2D GIS and 3D Scene [J]. Journal of Surveying and Mapping. 2007 (03)

[2] Xie Yilin, Wang Yunjia, Zhu Wei, Wu Junhong. Study and application of virtual digital mine [J]. Mining Engineering. 2007 (01)

[3] Liu Dongqin, Xu Wenzhong. Study and Application of Integration of Urban Spatial Two-dimensional Information System and 3D Virtual Scene [J].

[4] Xie Yilin, Wang Yunjia. Application of Virtual Scene to Realize 3DGIS Research and Application [J]. Surveying and Mapping Engineering. 2006 (06)

[5] Fu Yongming, Wang Yunjia. Discussion on mine scene simulation technology [J]. Journal of Computer Applications and Software. 2006 (04)

[6] Liu Yuliang, Shen Yingchun, Chen Wei, Chen Juan. Design and Implementation of a Two-dimensional Situation Display and 3D Vision Integration System [J]. Ship Electronic Engineering. 2005 (05)

[7] Yin Wensheng, Dau Lihong. Two-three-dimensional interactive scene simulation system based on MFC and Vega [J]. Computer Simulation. 2005 (05) 